\title{
Normal tissues toxicities triggered by combined anti-angiogenic and radiation therapies: hurdles might be ahead
}

\author{
M Mangoni ${ }^{1,2,3}$, M-C Vozenin ${ }^{*, 1,2}$, G Biti $^{3}$ and E Deutsch ${ }^{1,2}$ \\ 'Unité Mixte de Recherche 'radiothérapie moléculaire'. INSERM Unité 1030, Institut Gustave Roussy, PRI, I I 4, Rue E Vaillant, LabEx Lermit, 94805 \\ Villejuif CEDEX, France; ${ }^{2}$ Université Paris XI, Faculté de médecine le Kremlin-Bicêtre, France; ${ }^{3}$ Department of Clinical Physiopathology, Radiotherapy Unit, \\ University of Florence, Viale Morgagni 85, 50134 Firenze, Italy
}

BACKGROUND: Combined-modality therapy is a promising approach to improve the therapeutic index of radiotherapy. However, these improvements could come at the cost of increased toxicities. Clinical trials evaluating anti-tumour efficacy of bevacizumab combined with radiotherapy have encountered unexpected side effects. This study is the first systematic evaluation of normal tissue toxicity triggered by anti-angiogenic agents combined with radiation therapy in mice.

METHODS: Effect of a mouse anti-VEGF antibody was monitored on acute toxicity studying radiation-induced intestinal ulceration ( I 2 Gy TBI); on subacute toxicity using a model of oral mucositis ( $6.5 \mathrm{~Gy}$ ); on late radiation injuries by monitoring lung fibrosis (bleomycin and 19 Gy).

RESULTS: Combination of irradiation with anti-VEGF antibody enhanced intestinal damages with severe epithelial ulcerations, had no adverse impact on oral mucositis and dramatically worsened the fibrotic picture induced by bleomycin and irradiation to the lung. INTERPRETATION: These reports bring to light the important questions about safety and underscore the need for appropriate preclinical modelling of the impact on normal tissues of novel drug-radiation regimens. Our findings also highlight the complexity of anti-VEGF action, which could in defined conditions exert tissue-specific protection. The findings indicate that the combination of targeted drugs with radiotherapy should be approached with caution.

British Journal of Cancer (2012) I 07, 308-314. doi:I0.1038/bjc.2012.236 www.bjcancer.com

Published online 12 June 2012

(C) 2012 Cancer Research UK

Keywords: anti-VEGF antibody; radiation; toxicity

Drugs developed to inhibit angiogenesis have now entered routine clinical practice in anticancer therapies. However, in most cases no permanent tumour control can be achieved, therefore the combination of anti-angiogenic strategies with cytotoxic agents such as chemotherapy, ionising radiation, or both represents a promising approach to increase cure rate of solid tumours (Koukourakis, 2001; Jain, 2005). Unfortunately angiogenesis is not tumour restricted but is also found in many other physiological and pathological conditions, for example, normal growth, wound healing and inflammation (Carmeliet and Jain, 2000) hence, inhibition of angiogenesis combined with other treatment may increase normal tissue toxicity. US Food and Drug Administration has published a warning regarding the use of the anti-angiogenic agent bevacizumab (Avastin) in combination with chest radiotherapy (http://www.fda.gov/medwaTCH/safety/2007/Avastin_DHCP_ TEF_Final8April2007.pdf) and several publications now report serious adverse events especially after treatment of thorax, gastrointestinal tract, head and neck and brain malignancies combining bevacizumab and radiotherapy (Willett et al, 2005; Crane et al, 2006; Carden et al, 2008; Seiwert et al, 2008; Gutin et al, 2009; Spigel et al, 2010; Lai et al, 2011). Most of these studies aimed at evaluating the anti-tumour efficacy of combined bevacizumab concurrently with radiotherapy in poor outcome situations however the results obtained indicate the need for caution in the development of bevacizumab and related

*Correspondence: Dr M-C Vozenin; E-mail: vozenin@igr.fr

Received 25 January 2012; revised 25 April 2012; accepted 26 April 2012; published online 12 June 2012 drugs in combination with radiotherapy. Therefore, rather than discarding potential new drug combinations with radiotherapy, information regarding the possibility for unacceptable toxicities is needed and should be widely accessible to the cancer community prior to the initiation of clinical trials. One key issue is not only to find drugs that potentiate radiation response in tumour cells but also drugs that act selectively with a differential effect between normal tissue and tumour. For instance, gemcitabine's dramatic toxicity when combined with radiation in early trials would have been detected by appropriate preclinical experiments and a classical dose escalation phase I methodology (Scalliet et al, 1998). In a similar manner, bevacizumab transfer into the clinic in combination with radiotherapy was done after two well-performed phase I trials (Willett et al, 2005; Crane et al, 2006) but no preclinical research was performed to define normal tissue toxicities or the optimal window of treatment when combined with radiation. At the moment where academic radiotherapy centres are competing to select the most promising agents to be combined to radiotherapy, the selection of valid preclinical criteria must be emphasised to minimise exposure of patients to potentially harmful toxicities. Toxicities assessment represents a major preclinical challenge to anticipate side effects during clinical trials where the definitive results will impact the outcome of combinations (Deutsch et al, 2005). The aim of the present study was therefore to evaluate normal tissue damage combining bevacizumab with radiation. We used well-characterised, easy-to-handle and reproducible models of radiation-induced toxicity induced by single fraction irradiation in the gut (Withers and Elkind, 1970) (acute toxicity), oral mucosa (Parkins et al, 1983) (subacute toxicity) and lung (Haston 
and Travis, 1997; Monceau et al, 2010) (late toxicity), and we evaluated effect of a murin anti-VEGF antibody combined with radiotherapy with a robust preclinical study involving a large number of animals.

\section{MATERIALS AND METHODS}

\section{Reagent and animals}

Mouse anti-VEGF antibody VEGF MAb B20-4.1.1 was prepared from Genentech (Genentech, Vacaville, CA, USA) and dissolved in distilled water. Anti-VEGF antibody was administered intraperitoneally twice weekly at the dose of $5 \mathrm{mg} \mathrm{kg}^{-1}$ (Gerber and Ferrara, 2005).

All experiments were performed in accordance with European recommendations for the care and use of laboratory animals and Good Laboratory Practice. A total of 370 10- to 12-week-old female C57B6 mice (Janvier CERT 53940, Le Genest St Isle, France) entered the study ( $n>10$ mice per point). The experimental basal diet was solid food ad libitum (R.03 UAR, F91360, Villemoisson, France) and waster for the studies of radiation-induced intestinal damage and pulmonary toxicity and liquid food (Renutryl 500, Nestlé Clinical Nutrition, Marne La Vallée, France) and water for the study of radiation-induced mucositis.

\section{Radiation-induced intestinal damage (acute toxicity model)}

Total body irradiation (12 Gy) was performed to C57B6 mice. Un-anaesthetised mice were placed in prone position in an airventilated jig. Irradiation was delivered by a Philips RT250 $225 \mathrm{kV}$ $\mathrm{X}$-ray radiation source (Philips, Amsterdam, The Netherlands) with a $0.5 \mathrm{~mm} \mathrm{Cu}$ filter, at a dose rate of $0.69 \mathrm{~Gy} \mathrm{~min}^{-1}$. We observed effect of anti-VEGF antibody administered twice weekly beginning $24 \mathrm{~h}$ before irradiation. Then we created a chemically induced ulceration using intra-rectal administration of $150 \mathrm{mg} \mathrm{kg}^{-1}$ TNBS (2,4,6-trinitrobenzen sulphonic acid, SIGMA) (Schiffele and Fuss, 2002) prior to administration of the combined therapy with antiVEGF and irradiation (Figure 1A). Mice were killed $24 \mathrm{~h}$ or $72 \mathrm{~h}$ after irradiation and a $2-\mathrm{cm}$ ileum and colon segments were excised for histological analysis.

\section{Radiation-induced oral mucositis (subacute toxicity model)}

Mice were irradiated with a single dose of $16.5 \mathrm{~Gy}$ selectively on oral region. Irradiation was delivered by a Philips RT250 $225 \mathrm{kV}$ X-ray radiation source with a $0.5 \mathrm{~mm} \mathrm{Cu}$ filter, at a dose rate of $0.69 \mathrm{~Gy} \mathrm{~min}^{-1}$. Mice were irradiated ventrally, restrained by plastic supports without use of anaesthesia. The source-skin distance was $12.5 \mathrm{~cm}$. The whole body was shielded using a $18 \mathrm{~cm} \times 18 \mathrm{~cm}$ lead collimator $1 \mathrm{~cm}$ thick. The lead collimator had a central hole of $10 \mathrm{~cm}$ diameter for positioning in the irradiation field the anterior part of the snout that was not shielded. We evaluated effect on oral mucosa of anti-VEGF antibody administration $24 \mathrm{~h}$ before irradiation and then twice weekly for 3 weeks (Figure 2A). Mice were observed every day and mucosal reaction were scored using the Parkins scoring system (Table 1) (Parkins et al, 1983). On days 10 (pick of mucositis) or 22 , mice were killed and labial mucosa were collected.

\section{Lung fibrosis (late toxicity model)}

Mice were treated with the radio-mimetic agent bleomycin (Blenoxane) $40 \mathrm{mg} \mathrm{kg}^{-1}$ every 2 days for five administrations (Figure 3A) or with a single dose of $19 \mathrm{~Gy}$ irradiation (Figure 3C) (Haston and Travis, 1997; Monceau et al, 2010). For irradiation, mice were anaesthetised by isofluoran. The anaesthesia procedures began with mice rapidly induced sleep in an anaesthetic chamber and the subsequent positioning of the animals on the imaging system bed. Here mice were connected through a nose cone to breathe in anaesthetic gas, isofluorane (Forane, Abbott, Abbott Park, IL, USA) at $2-4 \%$ in $\mathrm{O}_{2}$, and breathe out excess anaesthetic gas to the same nose cone. Given that anaesthesia in general causes hypothermia in small animals, we provided appropriate warming during the irradiation procedure by the use of a heating lamp. Irradiation was delivered by a Tube Comet MXR-225/22 $200 \mathrm{kV}$ $\mathrm{X}$-ray radiation source (Comet, Flamatt, Switzerland) with a $0.2-\mathrm{mm} \mathrm{Cu}$ filter. The dose rate was $0.819 \mathrm{~Gy} \mathrm{~min}^{-1}$ and the source-skin distance was $19.8 \mathrm{~cm}$. Mice were irradiated in groups of three ventrally, restrained by plastic supports. The whole body was shielded using a $1-\mathrm{cm}$ lead collimator, at the exclusion of the pulmonary region. In the two models, we evaluated effect of $5 \mathrm{mg} \mathrm{kg}^{-1}$ anti-VEGF antibody started the day before bleomycin or irradiation and then repeated twice weekly for 2 weeks. At 32 days after the beginning of bleomycin administration or 15 weeks post irradiation, mice were killed and lungs were collected for histopathological analysis.

\section{Histological analysis}

Tissue specimens were first washed and then fixed in Finefix (Milestone, Torre Baldone (BG), Italy) for $24 \mathrm{~h}$. Then according to standard protocols, tissues were embedded in paraffin and 5-6 $\mu \mathrm{m}$ thick cross sections were prepared and stained with HaematoxylinEosin.

\section{RESULTS}

We studied the effects of an anti-VEGF antibody on acute toxicity in a model of radiation-induced intestinal and colonic ulceration obtained by $12 \mathrm{~Gy}$ total body irradiation. As expected $24 \mathrm{~h}$ later, $12-G y$ radiation-induced mucosal ulceration was observed with crypt dilatation, mucosal thickening, villi shortening and increased muco-secretion. Submucosa showed oedema and inflammatory infiltrate. Interestingly, combination of irradiation with the antiVEGF antibody enhanced damage with severe epithelial ulceration and glands exhibiting necrotic changes (Figure 1B). At $72 \mathrm{~h}$ post irradiation, the pathogenic picture dramatically worsened with decrease of the mucosal surface and villi shortening associated with submucosal oedema and inflammation further exacerbated by treatment with VEGF antibody. Our observations were confirmed repeating the experiment in a large number of animals $(n=80)$. Then, we reasoned that cancer patient often undergo various anticancer treatment regimens and are very likely to have an altered gastrointestinal mucosa that could worsen bevacizumab toxicity. Therefore, to evaluate if previous noxa interferes with effects of anti-VEGF antibody on irradiated gut, we created a chemically induced ulceration using intra-rectal administration of TNBS prior to administration of the combined therapy (Figure 1A). Treatment with intra-rectal TNBS before irradiation caused a modest worsening of radiation-induced mucosal injury on the colon. The association of anti-VEGF antibody dramatically increased TNBS and radiation-induced ulceration. The number of glands appeared drastically reduced and the mucosa showed a massive necrosis prone to fistula formation. (Figure 1C). Our observations recalled severe side effects reported in clinical studies testing Avastin and radiotherapy in rectal cancer.

Successively, we investigated the effects of an anti-VEGF antibody in a model of subacute radiation-induced toxicity on oral mucosa. Local irradiation of the mouse mouth at $16.5 \mathrm{~Gy}$ was used to generate oral mucositis. Mucosal reactions were evaluated everyday using Parkins score (Figure 2B) and sampling for histopathological examination was performed at two different times: 10 days after irradiation, that is the peak of mucosal reaction, and 22 days after irradiation after the restoration phase (Figures 2B and C). Histological analysis of un-irradiated mucosa showed were thin tissue, with a smooth keratinised epithelium, 

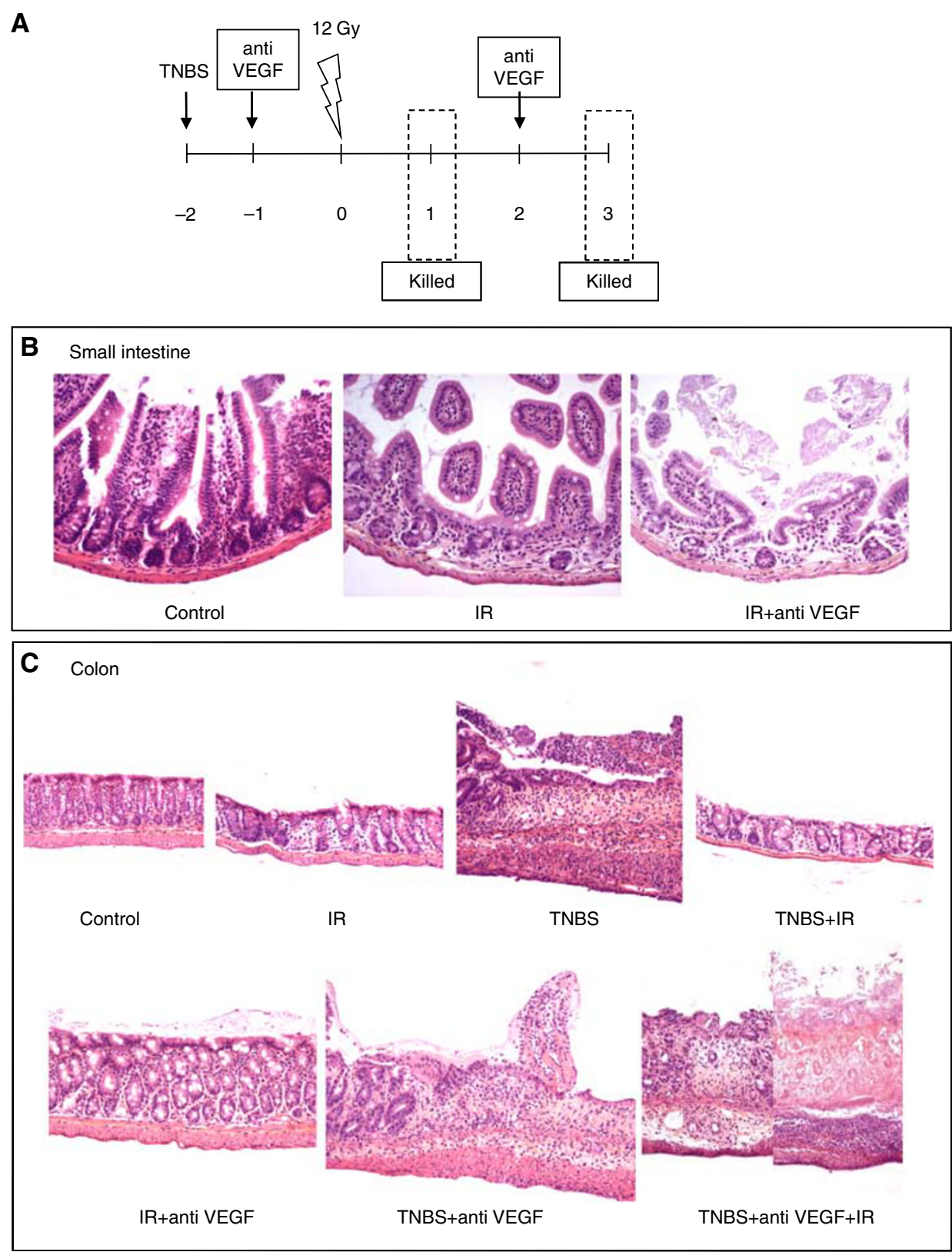

Figure I Acute toxicity: six groups of treatment were compared: (I) I2 Gy TBl; (2) anti-VEGF antibody at 5 mg kg ${ }^{-1}$ twice weekly beginning $24 \mathrm{~h}$ before 12 Gy TBI; (3)TNBS (I50 $\mathrm{mg} \mathrm{kg}^{-1}$ ); (4) TNBS before $12 \mathrm{~Gy}$ TBI; (5) TNBS before anti-VEGF antibody twice weekly; (6) TNBS before anti-VEGF antibody twice weekly and TBI 12 Gy. Mice were killed $24 \mathrm{~h}$ and $72 \mathrm{~h}$ after according to the schedule shown (A). At $24 \mathrm{~h}$ after irradiation small intestine histology (transversal sections) shows crypt dilatation, mucosal thickness and villi shortening. Anti-VEGF antibody enhances damages (B). At $24 \mathrm{~h}$ after irradiation colon histology (longitudinal sections) shows that mouse anti-VEGF antibody increases dramatically irradiation and TNBS-induced lesions (C).

a rectilinear basement membrane, a submucosal layer and a muscle bundle layer. The submucosa was primarily fibrous, with a scanty cell population and a few blood vessels. At 10 days after 16.5 Gy irradiation, epidermal thickening was the most obvious finding, however the submucosa showed deep oedema and damaged follicles reduced in number as well as increased collagen deposition. The number of inflammatory cells infiltrating the dermis and subcutaneous tissue was increased as compared with that found in normal mucosa (Figure 2C). Surprisingly, administration of the mouse anti-VEGF antibody did not worsen oral mucositis suggesting a tissue-specific activity of anti-VEGF antibody. The anti-VEGF antibody alone had no effect on mucosal structure. At 22 days after irradiation, the tissue almost totally recovered in all the groups of treatment (Figures $2 \mathrm{~B}$ and $\mathrm{C}$ ).
Finally we evaluated the effect of the anti-VEGF antibody in a model of late radiation-induced damage. Late radiation injuries were investigated by studying lung fibrosis. Pulmonary fibrosis was generated with administration of bleomycin, a radio-mimetic agent or with a single dose of irradiation (19Gy) that allow, respectively, occurrence of fibrosis within 30 days and 15 weeks post irradiation (Figures 3A and C). Bleomycin (Figure 3B.2) and irradiated (Figure 3D.1) groups typically showed a patchy subpleural and intra-parenchymal fibrosis with some local inflammatory infiltrate. Irradiation induced more severe fibrosis than bleomycin. The concurrent administration of the anti-VEGF antibody dramatically worsened fibrosis in both models. Inflammatory patches surrounded vessels and ruptures of the vascular wall located in the medium/large-sized vessels were observed 
A

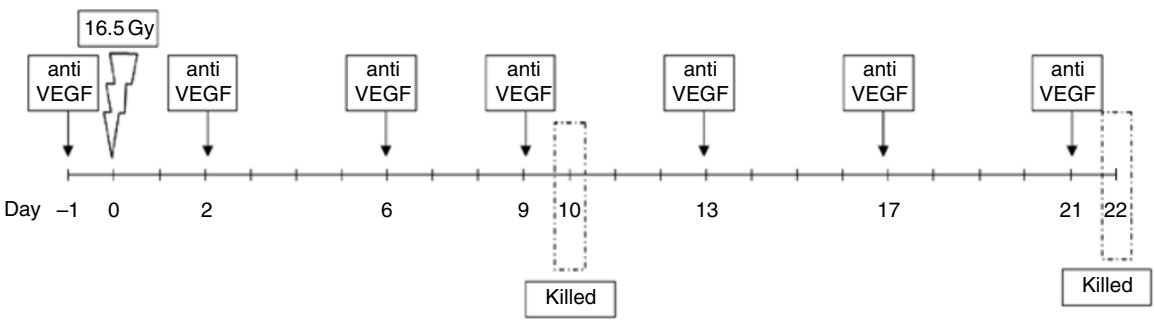

B
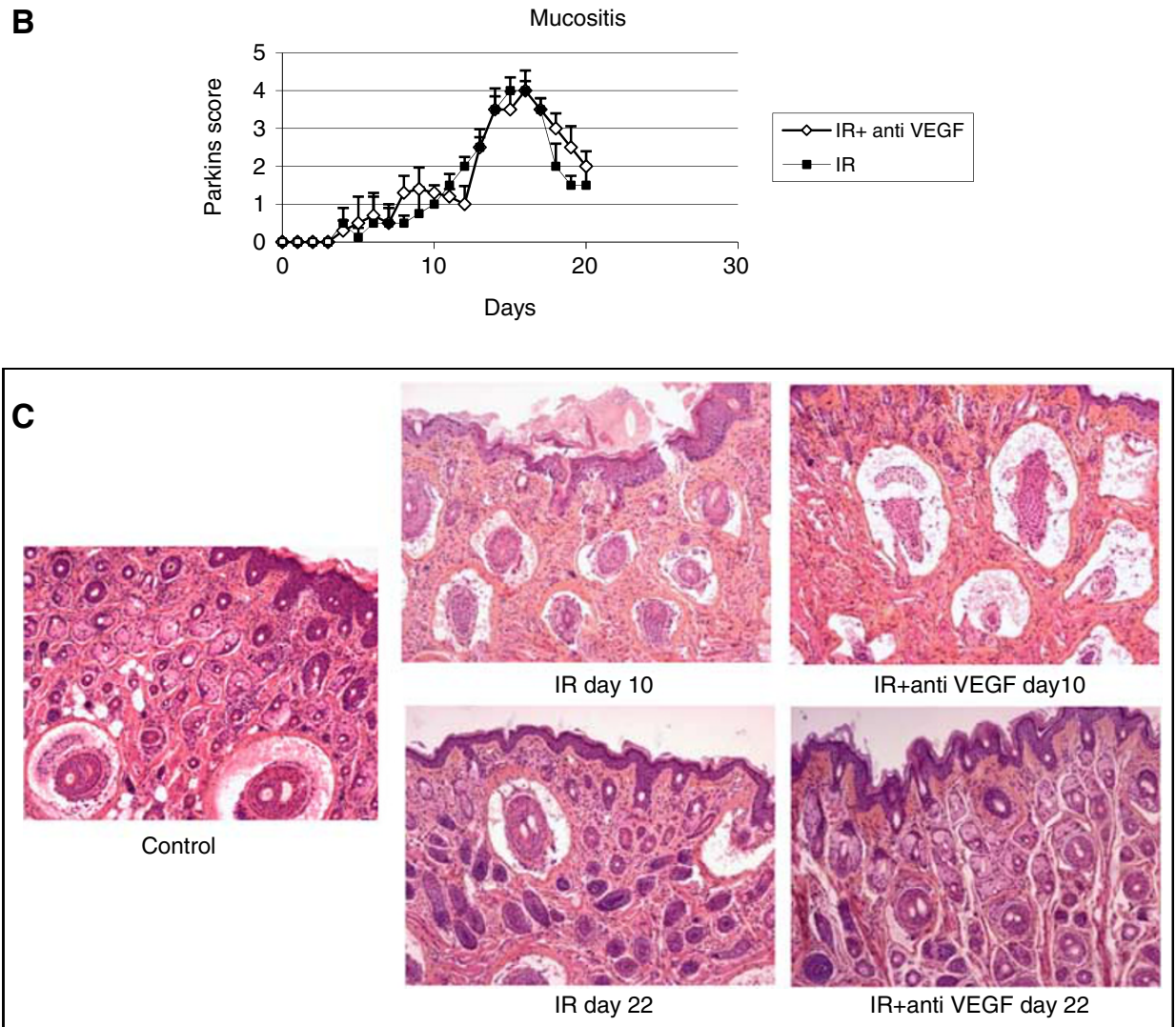

Figure 2 Monitoring subacute toxicity: oral mucositis was obtained after local snout irradiation at $16.5 \mathrm{~Gy}$ (A). We compared mice treated with or without anti-VEGF antibody at $5 \mathrm{mg} \mathrm{kg}^{-1}$ twice weekly beginning $24 \mathrm{~h}$ before irradiation. Intensity of the damages was monitored using Parkins score every day $(\mathbf{B})$. Animals were killed and sampled at day 10 and 22 and histopathological analysis performed on HES section (C).

(Figures 3B.3, 4 and 3D.2). The most probable explanation lie on the vascular effect of anti-VEGF therapy, as active angiogenic process is required for proper wound healing.

\section{DISCUSSION}

The present study is the first to show in experimental models that combination of irradiation with the mouse anti-VEGF antibody enhanced acute radiation-induced intestinal toxicity and that the deleterious effect was considerably enhanced when mucosa was previously injured. In addition, combination of anti-VEGF antibody with bleomycine or with irradiation dramatically worsened delayed toxicity with enhancement of pulmonary fibrosis associated with rupture of vascular walls. Our experiments also showed an interference of the anti-VEGF antibody with normal tissue response to irradiation that seemed tissue specific, as in oral mucositis no enhancement of the deleterious effect was observed. We are aware that single-dose irradiation is a regimen that is not conventionally used into the clinic and therefore the possibility that the normal tissue reactions after fractionated irradiation could
Table I Parkins scoring system for lip reactions of mice

\begin{tabular}{cl}
\hline Oedema score & $50-50$ doubtful if any swelling \\
0.5 & Slight but definite swelling \\
1 & Severe swelling \\
2 & \\
& \\
Erythema or exudation score & $50-50$ doubtful if abnormally pink \\
0.5 & Slight but definite redding \\
1 & Severe redding \\
2 & Focal desquamation \\
3 & Exudate or crusting involving about half lip area \\
4 & Exudate or crusting involving more than half lip area \\
5 &
\end{tabular}

be different given the alpha/beta of normal tissues. However, our data clearly suggest that radiation alone using this high-dose regimen, as well as the fibrosis-inducing agent bleomycin induce more damage when combined to VEGF blockade as compared with irradiation or bleomycin alone. These results are in full accordance with observations made in clinical trials in which combination of 
A

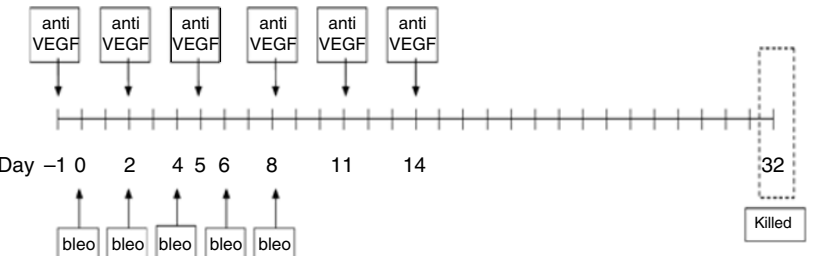

B

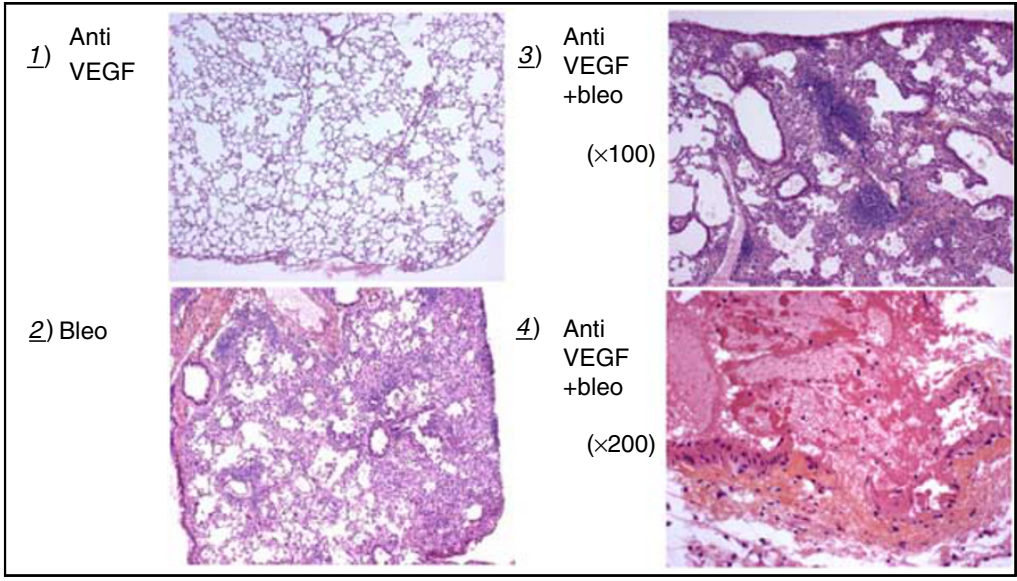

C

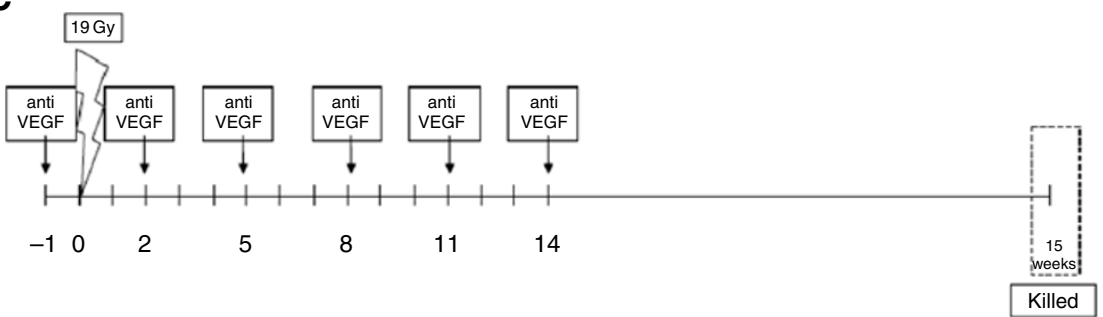

D

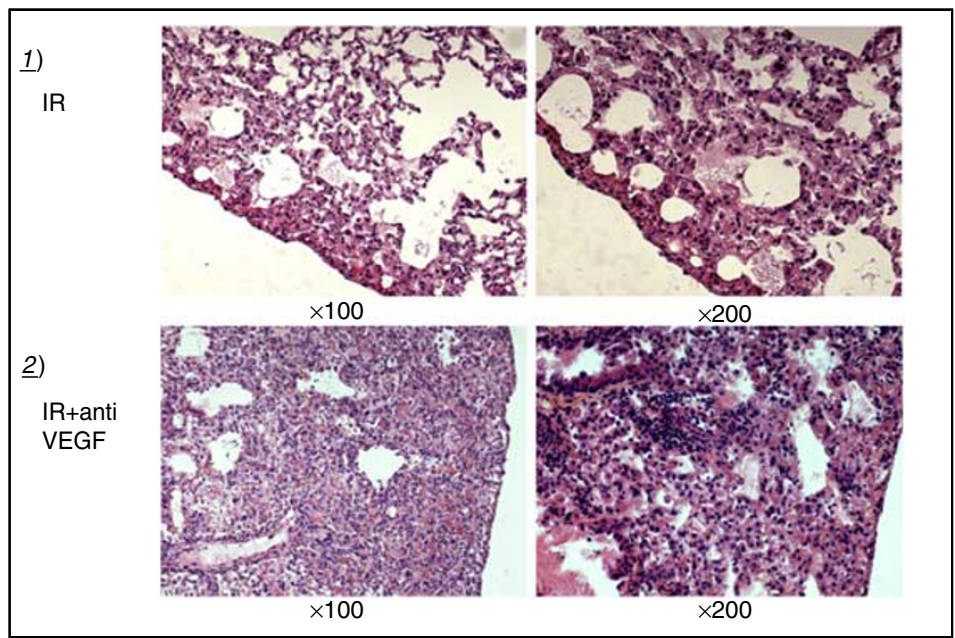

Figure 3 Late toxicity: effect of murine anti-VEGF antibody on the development of bleomycin and radiation-induced lung fibrosis was investigated. Lung fibrosis was generated using a radio-mimetic agent bleomycin and a single dose of irradiation (19 Gy) that allows, respectively, occurrence of fibrosis within 30 days and 15 weeks. Treatment schedule is shown in $(\mathbf{A})$ and $(\mathbf{C})$. Mice were killed and lungs collected for histopathological analysis at indicated times (B) and (D).

bevacizumab with radiotherapy have shown unexpected dramatic toxicities. Bevacizumab induced intestinal fistula in patients previously treated by abdominal irradiation (Lordick et al, 2006), suggesting an alteration of the wound-healing process in normal tissues when the anti-VEGF antibody is used during radiotherapy. Occurrence of tracheoesophageal fistula was reported in patients with limited-stage small cell lung cancer (Spigel et al, 2010) enroled in a phase II study combining concurrent irinotecan, carboplatin, radiation therapy and bevacizumab, followed by bevacizumab maintenance. Two confirmed serious adverse events of tracheoesophageal fistula were reported in the first 29 patients enroled and a third, fatal event (upper aerodigestive tract 
haemorrhage) was also reported, in which tracheoesophageal fistula was suspected but not confirmed. All three events occurred during the bevacizumab maintenance phase of the study in the context of persistent esophagitis. In another phase II trial conducted in locally advanced non-small-cell lung cancer, patients were thought to receive concurrent chemo-radiotherapy in combination with bevacizumab but enrolment was limited to five patients and closed early due to tracheoesophageal fistulae formation (Spigel et al, 2010). Tracheoesophageal fistulae are recognised, but are rare complications of lung cancer radiotherapy. An incidence of four confirmed fistulae and a suspected fifth among 34 total patients is therefore indicative of an enhanced toxicity. Bevacizumab's unique role is inhibition of angiogenesis and consequently delayed wound healing may account for this rare and serious effect. Recently, a phase I study for inoperable stage III non-small-cell lung cancer was stopped after a total of six patients with grade 2 and 3 radiation pneumonitis (Lind et al, 2012).

In patients with locally advanced pancreatic cancer, a phase I trial evaluating the safety of bevacizumab with concurrent radiotherapy and capecitabine (Crane et al, 2006), four patients had grade 3 or greater ulceration with bleeding or perforation in the radiation field probably related to bevacizumab. After the protocol was amended, total bevacizumab dose was decreased and patients with tumours invading the duodenum seen on CT scan or endoscopy were excluded. Despite the overall tolerability of this last regimen, the four subacute adverse events (ulceration, bleeding, perforation) reported in the radiation field are concerning. These events occurred between 3 and 20 weeks after the completion of chemo-radiotherapy and for bevacizumab doses ranging from 2.5 to $7.5 \mathrm{mg} \mathrm{kg}^{-1}$. In another phase I trial of bevacizumab dose escalation with radiotherapy in rectal cancer, five patients received high dose of bevacizumab $\left(10 \mathrm{mg} \mathrm{kg}^{-1}\right)$ combined with chemotherapy. Radiotherapy induced two complete responses in locally advanced rectal cancer patients, but also induced dose-limiting toxicity in two patients (Willett et al, 2005). More recently, in a phase I trial evaluating the maximum-tolerated dose and dose-limiting toxicity of bevacizumab, when added to fluorouracil, hydroxyurea and radiation therapy in patients with poor prognosis head and neck cancer, 5 of 43 patients experienced fistula formation $(11.6 \%)$ and 4 ulceration/tissue necrosis $(9.3 \%)$ (Seiwert et al, 2008).

Alteration of the wound-healing process is also the most probable explanation of the observed enhancement of the fibrotic picture. There are few preclinical reports on the effect of the antiVEGF antibody on wound healing. Bevacizumab has been shown to reduce the rate of spontaneous wound healing in macaques (Cornacoff et al, 2008). Agent targeting VEGF have demonstrated deleterious effects on the healing of ventral hernias and colonic anastomoses (Hendriks et al, 1999; Howdieshell et al, 2001; te Velde et al, 2002) and a VEGFR2 antibody has been shown to reduce the regenerative capacity of partially resected mice liver (Van Buren et al, 2008). Wound-healing complications are of concern in patients undergoing surgery. The vast majority of wound-healing complications reported in patients treated with anti-angiogenic agents occurred in the early post-operative period (Clark et al, 2011; Erinjeri et al, 2011; Pietzner et al, 2011), therefore major surgery less than 28 days before the beginning of therapy has been an exclusion criterion in colorectal phase II and III studies with bevacizumab (Kabbinavar et al, 2003; Hurwitz et al, 2004; Kabbinavar et al, 2005). However, recently antiangiogenetic agents have been associated also with complication long after the surgery (Deshaies et al, 2010). Vascular changes induced by anti-VEGF antibody could be responsible of an impaired supply of cytokines and soluble factors necessary to recover damaged tissue that remains to be investigated (Howdieshell et al, 2001). Actually, on www.clinicaltrials.gov, we found 365 registered studies with search as 'interventions' of 'bevacizumab and radiation therapy', 130 of them are still being recruited. Related early and late tissue-specific toxicities could eventually be highly relevant.

To our knowledge, these experiments are the first systematic studies investigating normal tissue toxicity in mice treated with monoclonal antibodies raised against (murine) VEGF combined with radiation therapy. Our results may have significant clinical implications and are in agreement with previously reported toxicities during clinical trials. Other findings reported here are even more concerning as they indicate a potential for late toxicities that are as yet unreported, but that could be expected. They suggest the necessity of careful long-term follow-up of the patients who have undergone such combined treatments. The results obtained in the model of subacute toxicity also highlight the complexity of anti-VEGF action, which could in defined conditions exert tissue-specific mucosal protection.

In the future, investigation of tissue-specific toxicities is highly relevant and the case of brain tumour is of primary importance. Concerns over a potential increase in the incidence of intracranial bleeding have been raised over the safety of bevacizumab for the treatment of the central nervous system (CNS) tumours (Carden et al, 2008). In a phase II study of bevacizumab plus temozolomide conducted on 70 newly diagnosed glioblastoma's patients, 2 cases of CNS haemorrhage were reported (Lai et al, 2011). In another study on patients with recurrent glioblastoma and anaplastic gliomas receiving bevacizumab with hypofractionated stereotactic irradiation, 1 of 25 patients experienced a grade 3 CNS intratumoural haemorrhage (Gutin et al, 2009). However, bevacizumab has also been prescribed to treat radiation-induced necrosis (Gonzalez et al, 2007; Wong et al, 2008; Levin et al, 2011) but controversial findings are reported about the effects of bevacizumab on radiation necrosis of the CNS. The mechanism of radiation necrosis appears to be a result of radiation damage to vascular endothelial cells, causing endothelial cell proliferation, telangiectatic vessels and fibrinoid necrosis with accompanying perivascular exudation and oedema (Llena et al, 1976), thus, blocking VEGF from reaching its capillary targets is a logical treatment strategy for radiation necrosis. Several case reports and a randomised double-blind placebo-controlled trial have described the use of bevacizumab as a therapeutic option for cerebral radiation necrosis however exacerbation of cerebral radiation necrosis by bevacizumab has been reported (Jeyaretna et al, 2011).

In summary, the present experiments were designed to investigate toxicity of bevacizumab and radiation combination in simple and well-defined experimental models and should persuade them to use combination of targeted drugs with radiotherapy with caution. However, it is also clear that further investigations are required to decipher the mechanisms involved in both the toxicity and protection observed, to optimise these treatment regimens and to define countermeasures to obtain safe and efficient treatment that is of net benefit to patients. In considering the experimental findings required to move a drug-radiation combination regimen forward from the laboratory to the clinic, our data support the necessity for preclinical evaluation of the consequences on normal tissue response. In the case of monoclonal antibodies targeting VEGF or EGFR, the lack of cross-reactivity between human and murine epitopes is particularly challenging for the toxicity assessment, thus requiring the use of equivalent anti-murine epitope monoclonal antibodies. The findings obtained here therefore address the potential toxicities of anti-VEGF strategies combined with radiation treatment, rather than a particular reagent.

\section{ACKNOWLEDGEMENTS}

The study was supported by ARC funding no. 4970. We would like to thank Dr E Bernhard for reading the manuscript, D Violot for help in irradiation procedures, O Bawa for technical assistance in histology and SCEA for mice care. 


\section{REFERENCES}

Carden CP, Larkin JM, Rosenthal MA (2008) What is the risk of intracranial bleeding during anti-VEGF therapy? Neuro Oncol 10: 624-630

Carmeliet P, Jain RK (2000) Angiogenesis in cancer and other diseases. Nature 407: 249-257

Clark AJ, Butowski NA, Chang SM, Prados MD, Clarke J, Polley MY, Sughrue ME, McDermott MW, Parsa AT, Berger MS, Aghi MK (2011) Impact of bevacizumab chemotherapy on craniotomy wound healing. J Neurosurg 114: 1609-1616

Cornacoff JB, Howk K, Pikounis B, Mendenhall V, Martin P (2008) Development of a method for the evaluation of wound tensile strength in cynomolgus macaques. J Pharmacol Toxicol Methods 57: 74-79

Crane CH, Ellis LM, Abbruzzese JL, Amos C, Xiong HQ, Ho L, Evans DB, Tamm EP, Ng C, Pisters PW, Charnsangavej C, Delclos ME, O’Reilly M, Lee JE, Wolff RA (2006) Phase I trial evaluating the safety of bevacizumab with concurrent radiotherapy and capecitabine in locally advanced pancreatic cancer. J Clin Oncol 24: 1145-1151

Deshaies I, Malka D, Soria JC, Massard C, Bahleda R, Elias D (2010) Antiangiogenic agents and late anastomotic complications. J Surg Oncol 101: $180-183$

Deutsch E, Soria JC, Armand JP (2005) New concepts for phase I trials: evaluating new drugs combined with radiation therapy. Nat Clin Pract Oncol 2: 456-465

Erinjeri JP, Fong AJ, Kemeny NE, Brown KT, Getrajdman GI, Solomon SB (2011) Timing of administration of bevacizumab chemotherapy affects wound healing after chest wall port placement. Cancer 117: 1296-1301

Gerber HP, Ferrara N (2005) Pharmacology and pharmacodynamics of bevacizumab as monotherapy or in combination with cytotoxic therapy in preclinical studies. Cancer Res 65: 671-680

Gonzalez J, Kumar AJ, Conrad CA, Levin VA (2007) Effect of bevacizumab on radiation necrosis of the brain. Int J Radiat Oncol Biol Phys 67: $323-326$

Gutin PH, Iwamoto FM, Beal K, Mohile NA, Karimi S, Hou BL, Lymberis S, Yamada Y, Chang J, Abrey LE (2009) Safety and efficacy of bevacizumab with hypofractionated stereotactic irradiation for recurrent malignant gliomas. Int J Radiat Oncol Biol Phys 75: 156-163

Haston CK, Travis EL (1997) Murine susceptibility to radiation-induced pulmonary fibrosis is influenced by a genetic factor implicated in susceptibility to bleomycin-induced pulmonary fibrosis. Cancer Res 57 5286-5291

Hendriks JM, Hubens G, Wuyts FL, Vermeulen P, Hubens A, Eyskens E (1999) Experimental study of intraperitoneal suramin on the healing of colonic anastomoses. Br J Surg 86: 1171-1175

Howdieshell TR, Callaway D, Webb WL, Gaines MD, Procter Jr CD, Sathyanarayana, Pollock JS, Brock TL, McNeil PL (2001) Antibody neutralization of vascular endothelial growth factor inhibits wound granulation tissue formation. J Surg Res 96: 173-182

Hurwitz H, Fehrenbacher L, Novotny W, Cartwright T, Hainsworth J, Heim W, Berlin J, Baron A, Griffing S, Holmgren E, Ferrara N, Fyfe G, Rogers B, Ross R, Kabbinavar F (2004) Bevacizumab plus irinotecan, fluorouracil, and leucovorin for metastatic colorectal cancer. $N$ Engl J Med 350: 2335-2342

Jain RK (2005) Normalization of tumor vasculature: an emerging concept in antiangiogenic therapy. Science 307: 58-62

Jeyaretna DS, Curry Jr WT, Batchelor TT, Stemmer-Rachamimov A, Plotkin SR (2011) Exacerbation of cerebral radiation necrosis by bevacizumab. J Clin Oncol 29: e159-e162

Kabbinavar F, Hurwitz HI, Fehrenbacher L, Meropol NJ, Novotny WF, Lieberman G, Griffing S, Bergsland E (2003) Phase II, randomized trial comparing bevacizumab plus fluorouracil (FU)/leucovorin (LV) with FU/LV alone in patients with metastatic colorectal cancer. J Clin Oncol 21: $60-65$

Kabbinavar FF, Schulz J, McCleod M, Patel T, Hamm JT, Hecht JR, Mass R, Perrou B, Nelson B, Novotny WF (2005) Addition of bevacizumab to bolus fluorouracil and leucovorin in first-line metastatic colorectal cancer: results of a randomized phase II trial. J Clin Oncol 23: 3697-3705

Koukourakis MI (2001) Tumour angiogenesis and response to radiotherapy. Anticancer Res 21: 4285-4300
Lai A, Tran A, Nghiemphu PL, Pope WB, Solis OE, Selch M, Filka E, Yong WH, Mischel PS, Liau LM, Phuphanich S, Black K, Peak S, Green RM, Spier CE, Kolevska T, Polikoff J, Fehrenbacher L, Elashoff R, Cloughesy T (2011) Phase II study of bevacizumab plus temozolomide during and after radiation therapy for patients with newly diagnosed glioblastoma multiforme. J Clin Oncol 29: 142-148

Levin VA, Bidaut L, Hou P, Kumar AJ, Wefel JS, Bekele BN, Prabhu S, Loghin M, Gilbert MR, Jackson EF (2011) Randomized doubleblind placebo-controlled trial of bevacizumab therapy for radiation necrosis of the central nervous system. Int J Radiat Oncol Biol Phys 79: 1487-1495

Lind JSW, Senan S, Smit EF (2012) Pulmonary toxicity after bevacizumab and concurrent thoracic radiotherapy observed in a phase I study for inoperabile stage III non-small-cell lung cancer. J Clin Oncol 30: e104-e108

Llena JF, Cespedes G, Hirano A, Zimmerman HM, Feiring EH, Fine D (1976) Vascular alterations in delayed radiation necrosis of the brain. An electron microscopical study. Arch Pathol Lab Med 100: 531-534

Lordick F, Geinitz H, Theisen J, Sendler A, Sarbia M (2006) Increased risk of ischemic bowel complications during treatment with bevacizumab after pelvic irradiation: report of three cases. Int J Radiat Oncol Biol Phys 64: $1295-1298$

Monceau V, Pasinetti N, Schupp C, Pouzoulet F, Opolon P, Vozenin MC (2010) Modulation of the Rho/ROCK pathway in heart and lung after thorax irradiation reveals targets to improve normal tissue toxicity. Curr Drug Targets 11(11): 1395-1404

Parkins CS, Fowler JF, Yu S (1983) A murine model of lip epidermal/ mucosal reactions to X-irradiation. Radiother Oncol 1: 159-165

Pietzner K, Richter R, Chekerov R, Erol E, Oskay-Ozcelik G, Lichtenegger W, Sehouli J (2011) Bevacizumab in heavily pre-treated and platinum resistant ovarian cancer: a retrospective study of the North-Eastern German Society of Gynaecologic Oncology (NOGGO) Ovarian Cancer Study Group. Anticancer Res 31: 2679-2682

Scalliet P, Goor C, Galdermans D, Van Meerbeck J, Groen H, Van de Leest A (1998) Gemzar $\mathbb{R}$ (gemcitabine) with thoracic radiotherapy - a phase II pilot study in chemonaive patients with advanced non-small cell lung cancer. Proc Am Soc Clin Oncol 17: 499a

Schiffele F, Fuss IJ (2002) Induction of TNBS colitis in mice. Curr Protoc Immunol 15: 15-19

Seiwert TY, Haraf DJ, Cohen EE, Stenson K, Witt ME, Dekker A Kocherginsky M, Weichselbaum RR, Chen HX, Vokes EE (2008) Phase I study of bevacizumab added to fluorouracil- and hydroxyureabased concomitant chemoradiotherapy for poor-prognosis head and neck cancer. I Clin Oncol 26: 1732-1741

Spigel DR, Hainsworth JD, Yardley DA, Raefsky E, Patton J, Peacock N, Farley C, Burris 3rd HA, Greco FA (2010) Tracheoesophageal fistula formation in patients with lung cancer treated with chemoradiation and bevacizumab. J Clin Oncol 28: 43-48

te Velde EA, Voest EE, van Gorp JM, Verheem A, Hagendoorn J, Gebbink MF, Borel Rinkes IH (2002) Adverse effects of the antiangiogenic agent angiostatin on the healing of experimental colonic anastomoses. Ann Surg Oncol 9: 303-309

Van Buren II G, Yang AD, Dallas NA, Gray MJ, Lim SJ, Xia L, Fan F, Somcio R, Wu Y, Hicklin DJ, Ellis LM (2008) Effect of molecular therapeutics on liver regeneration in a murine model. J Clin Oncol 26: $1836-1842$

Willett CG, Boucher Y, Duda DG, di Tomaso E, Munn LL, Tong RT, Kozin SV, Petit L, Jain RK, Chung DC, Sahani DV, Kalva SP, Cohen KS, Scadden DT, Fischman AJ, Clark JW, Ryan DP, Zhu AX, Blaszkowsky LS, Shellito PC, Mino-Kenudson M, Lauwers GY (2005) Surrogate markers for antiangiogenic therapy and dose-limiting toxicities for bevacizumab with radiation and chemotherapy: continued experience of a phase I trial in rectal cancer patients. J Clin Oncol 23: 8136-8139

Withers HR, Elkind MM (1970) Microcolony survival assay for cells of mouse intestinal mucosa exposed to radiation. Int J Radiat Biol Relat Stud Phys Chem Med 17: 261-267

Wong ET, Huberman M, Lu XQ, Mahadevan A (2008) Bevacizumab reverses cerebral radiation necrosis. J Clin Oncol 26: 5649-5650

This work is published under the standard license to publish agreement. After 12 months the work will become freely available and the license terms will switch to a Creative Commons Attribution-NonCommercial-Share Alike 3.0 Unported License. 